This document is the Accepted Manuscript version of a Published Work that appeared in final form in Journal of the American Chemical Society, copyright (c) American Chemical Society after peer review and technical editing by the publisher. To access the final edited and published work see:

https://dx.doi.org/10.1021/jacs. 9b08584. 


\title{
Highly Strained, Radially $\pi$-Conjugated Porphyrinylene Nanohoops
}

\author{
Youzhi Xu ${ }^{\dagger}$ Sebastian Gsänger, ${ }^{\ddagger}$ Martin B. Minameyer,${ }^{\S}$ Inhar Imaz,,${ }^{\xi}$ Daniel Maspoch,,${ }^{\xi}$ Oleksandr \\ Shyshov,${ }^{\dagger}$ Fabian Schwer, ${ }^{\dagger}$ Xavi Ribas, ${ }^{\#}$ Thomas Drewello, ${ }^{\S}$ Bernd Meyer,,$* *$ and Max von Delius ${ }^{\dagger}, *$
}

\begin{abstract}
'Institute of Organic Chemistry, University of Ulm, Albert-Einstein-Allee 11, 89081 Ulm, Germany.
*Interdisciplinary Center for Molecular Materials (ICMM) and Computer-Chemistry-Center (CCC), Friedrich-Alexander University Erlangen-Nürnberg, Nägelsbachstraße 25, 91052 Erlangen, Germany.

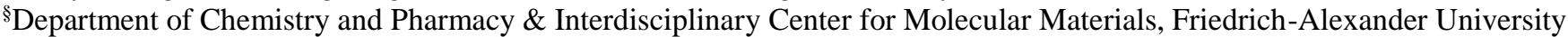
Erlangen-Nürnberg, Egerlandstrasse 3, 91058 Erlangen, Germany.

${ }^{\xi}$ Catalan Institute of Nanoscience and Nanotechnology (ICN2), CSIC and the Barcelona Institute of Science and Technology, Campus UAB, E-08193 Bellaterra, Barcelona (Catalonia, Spain).

"Institut de Química Computacional i Catàlisi and Departament de Química, Universitat de Girona, Campus Montilivi, E17003 Girona (Catalonia, Spain).
\end{abstract}

\begin{abstract}
Small $\pi$-conjugated nanohoops are difficult to prepare, but offer an excellent platform for studying the interplay between strain and optoelectronic properties and increasingly, these shape-persistent macrocycles find uses in host-guest chemistry and self-assembly. We report the synthesis of a new family of radially $\pi$-conjugated porphyrinylene/phenylene nanohoops. The strain energy in the smallest nanohoop [2]CPT is approximately $54 \mathrm{kcal} \mathrm{mol}^{-1}$, which results in a narrowed HOMO-LUMO gap and a red shift in the visible part of the absorption spectrum. Due to its high degree of preorganization and a diameter of ca. 13 $\AA$, [2]CPT was found to accommodate $\mathrm{C}_{60}$ with a binding affinity exceeding $10^{8} \mathrm{M}^{-1}$ despite the fullerene not fully entering the cavity of the host (XRay crystallography). Moreover, the $\pi$-extended nanohoops [2]CPTN , [3]CPTN and [3]CPTA (N for 1,4-naphthyl; A for 9,10anthracenyl) have been prepared using the same strategy, and [2]CPTN has been shown to bind $\mathrm{C}_{70}$ five times more strongly than [2]CPT. Our failed synthesis of [2]CPTA highlights a limitation of the experimental approach most commonly used to prepare strained nanohoops, because in this particular case the sum of aromatization energies no longer outweighs the buildup of ring strain in the final reaction step (DFT calculations). These results indicate that forcing ring strain onto organic semiconductors is a viable strategy to fundamentally influence both optoelectronic and supramolecular properties.
\end{abstract}

\section{INTRODUCTION}

Carbon-rich "nanohoops" exhibiting radial $\pi$-conjugation (Figure 1), such as the $[n]$ cycloparaphenylenes, have attracted much attention recently due to their challenging synthesis, intriguing optoelectronic properties and their vast potential in supramolecular chemistry. ${ }^{1}$ Macrocycles containing porphyrins have been pursued for several decades, ${ }^{2}$ leading to important advances in host-guest chemistry ${ }^{3}$ and catalysis. ${ }^{4}$ Most reported compounds, however, do not exhibit an uninterrupted conjugation pathway or significant ring strain. An exception regarding conjugation is Anderson's work on large porphyrin nanorings, ${ }^{1 \mathrm{~b}, 5}$ which has produced new concepts of template synthesis ${ }^{6}$ and spectacular insights into global (anti)aromaticity ${ }^{7}$ as well as charge delocalization. ${ }^{8}$ The smallest nanoring synthesized by Anderson features five porphyrin moieties linked by butadiyne spacers that appear to bear most of the moderate ring strain. ${ }^{9}$ Osuka's porphyrinelene/phenylene hybrids featuring three to six porphyrins within the macrocycle are subject to significant strain energies (up to $49 \mathrm{kcal} \mathrm{mol}^{-1}$ ). However, with a diameter of $16 \AA$, the smallest nanohoop of this series is still too large to effectively accommodate fullerenes. ${ }^{10}$
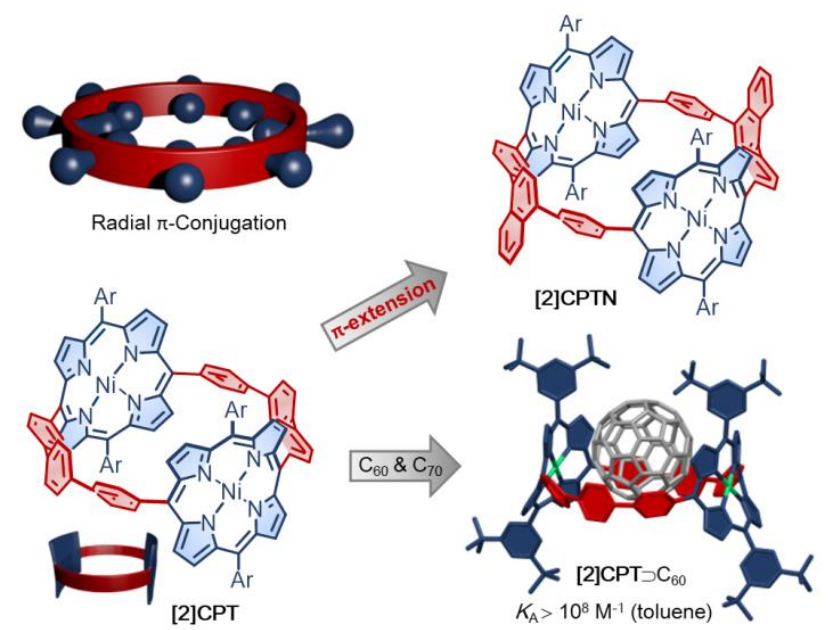

Figure 1. Radial $\pi$-conjugated porphyrinylene/phenylene nanohoop.

We wondered whether a smaller variant of Osuka's macrocycles would be accessible based on recent progress in the synthesis of highly strained macrocycles. ${ }^{11}$ Specifi- 
a)
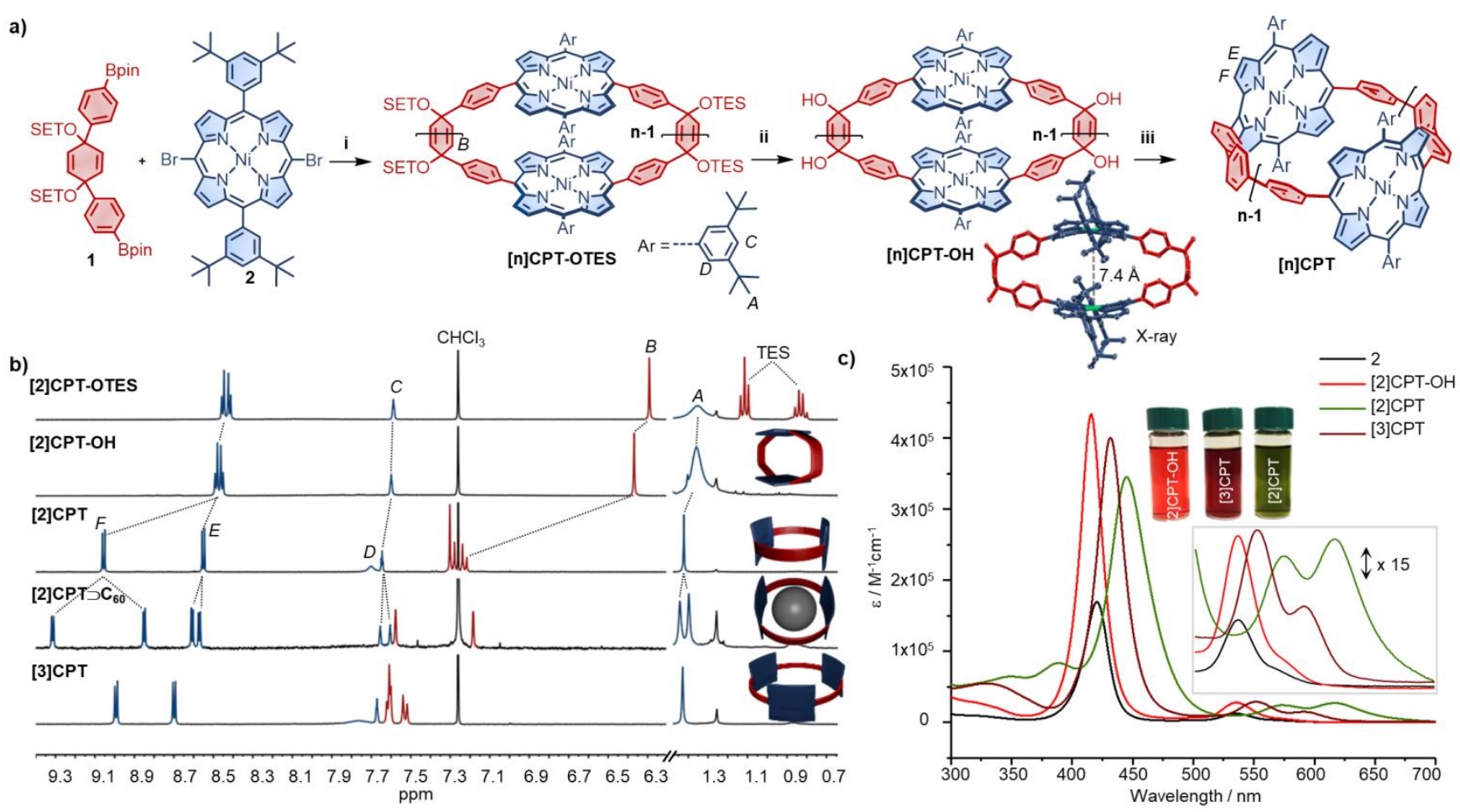

Figure 2. Synthesis of the [n]CPT. (a) Reaction conditions: (i) $\mathrm{Pd}\left(\mathrm{PPh}_{3}\right)_{4}, \mathrm{Cs}_{2} \mathrm{CO}_{3}$, pyridine, toluene, $125^{\circ} \mathrm{C}, 15 \mathrm{~h}$. (ii) TBAF, THF, RT, 1 h. (iii) $\mathrm{H}_{2} \mathrm{SnCl}_{4}, 0^{\circ} \mathrm{C} \rightarrow \mathrm{RT}, 12 \mathrm{~h}$, ([2]CPT 10\%, [3]CPT 8\% 3-step yield) . (b) Partial ${ }^{1} \mathrm{H}$ NMR spectra (CDCl 3 , $\left.298 \mathrm{~K}, 400 \mathrm{MHz}\right)$, [2]CPT-OTES, [2]CPT-OH, [2]CPT, [2]CPT $\supset \mathbf{C}_{60}$ and [3]CPT. (c) UV-vis absorption spectra of 2 (black) [2]CPT-OH (light red) [2]CPT (light green) and [3]CPT (dark red).

cally, we anticipated that [2]cyclo-5,15-porphrinylene-4,4', $4^{\prime \prime}-$ terphenyl ([2]CPT) would have a very similar diameter to $[10]$ cycloparaphenylene $([10] \mathrm{CPP})$, which has recently been shown to be an excellent host for $\mathrm{C}_{60},{ }^{12}$ enabling studies on noncovalent charge transfer ${ }^{13}$ and the synthesis of [2]rotaxanes. ${ }^{14}$ Herein we report that [2]CPT as highly strained porphyrinylene/phenylene nanohoop can be synthesized in seven linear steps. Although the calculated ${ }^{15}$ ring strain of $54 \mathrm{kcal} \mathrm{mol}^{-1}$ in this compound is not as high as in the smallest CPP ([5]CPP: $\left.119 \mathrm{kcal} \mathrm{mol}^{-1}\right),{ }^{16}$ we observed a strong influence of strain on the absorption and in contrast to the CPPs the bathochromic shift affects the visible part of the spectrum. We also prepared several $\pi$-extended analogues of [n]CPT and found that members of the [2]CPT nanohoop family are extremely effective receptors for $\mathrm{C}_{60}$ and $\mathrm{C}_{70}$ (e.g. Figure 1).

\section{RESULTS AND DISCUSSION}

Synthesis of Precursors. The key steps in the synthesis of [n]CPT are shown in Figure 2a. Diboronate 1 and meso-porphyrin $\mathbf{2}$ are accessible on a multigram scale in four and three linear steps, respectively. Under standard conditions for $\mathrm{Su}$ zuki-Miyaura cross-coupling $\left(125{ }^{\circ} \mathrm{C}\right.$, toluene, $\left.\mathrm{Cs}_{2} \mathrm{CO}_{3}\right)$, we found that the crucial ring-closing step only gave minuscule quantities of the desired small nanohoop [2]CPT-OTES. In a parameter optimization study for this reaction step, we discovered that the addition of pyridine (100 equiv.) led to a significantly increased yield of the desired macrocycle and an unexpected ratio between [2]CPT-OTES and [3]CPT-OTES of ca. $2: 1$. We initially attributed this effect to the binding of pyridine to the nickel center, but based on the $\mathrm{Ni}-\mathrm{Ni}$ distance of $7.4 \AA$ in the solid state structure of [2]CPT-OH (vide infra), we believe that a $\pi-\pi$ template effect between electron-deficient pyridine and the electron-rich porphyrins may be at work. As shown in Figure 2b, compound [2]CPT-OTES exhibits a broad peak in the ${ }^{1} \mathrm{H}$ NMR spectrum for the signal corresponding to the tertbutyl groups. Variable-temperature (VT) NMR spectroscopy and line-shape analysis allowed us to determine the kinetic parameters (e.g. $\Delta \mathrm{G}_{298}^{\ddagger}=58.9 \mathrm{~kJ} \mathrm{~mol}^{-1}$, Figure S3-5) for this process, which we attribute to hindered di-(tert-butyl)phenyl rotation due to steric clash between two tert-butyl groups on one face of the macrocycle (see Figure 3a, right hand side).

The isolated compounds $[\boldsymbol{n}]$ CPT-OTES underwent a smooth transformation into the corresponding alcohols $[\boldsymbol{n}] \mathbf{C P T}-\mathbf{O H}$ upon addition of a suitable fluoride reagent. Typically, we converted these intermediates immediately into the target compounds, but in one instance we attempted to purify compound [2]CPT-OH and were able to grow single crystals suitable for X-Ray crystallography. The solid state structure (Figure 2a) of this compound reveals a rectangular (slightly oval) shape with a Ni-Ni distance of $7.4 \AA$ and two porphyrin macrocycles with a "ruffle" geometry and an offset angle of $80^{\circ}$, which likely helps avoiding an unfavorable interaction between two tert-butyl groups. Because this compound could be of interest as a bimetallic catalyst, ${ }^{17}$ it is worth noting that in this solid state structure the cavity is populated by (masked) solvent molecules and that DFT studies point towards negligible ring strain (Table 1), as well as the ability to adopt a variety of conformations, including some with small cavity volumes (Figure S39).

Nanohoop Synthesis and Characterization. We found that the final aromatization step (Figure 2a) required rigorously optimized reaction conditions, which is presumably as a result 
Table 1. Selected properties of [2]CPT-OH, [3]CPT,[2]CPTN, [3]CPTN and [3]CPTA.

\begin{tabular}{cccccccc}
\hline Compound & $\begin{array}{c}\text { Strain Energy }^{a} \\
{\left[\mathrm{kcal} \mathrm{mol}{ }^{-1}\right]}\end{array}$ & $\begin{array}{c}\lambda_{\max }(\mathrm{S}, \mathrm{Q})^{b} \\
{[\mathrm{~nm}]}\end{array}$ & $\begin{array}{c}\varepsilon_{\max }^{b} \\
{\left[\mathrm{~L} \cdot \mathrm{mol}^{-1} \cdot \mathrm{cm}^{-1}\right]}\end{array}$ & $\begin{array}{c}E_{\text {Ox1 }}^{0}\left(E^{0}{ }_{\mathrm{Ox} 2}\right)^{c} \\
{[\mathrm{~V}]}\end{array}$ & $\begin{array}{c}E_{\text {red1 }}^{0}\left(E_{\text {red2 }}^{0}\right)^{c} \\
{[\mathrm{~V}]}\end{array}$ & $\begin{array}{c}\mathrm{HOMO}^{d} \\
{[\mathrm{eV}]}\end{array}$ & $\begin{array}{c}E_{\mathrm{g}}{ }^{e} \\
{[\mathrm{eV}]}\end{array}$ \\
\hline [2]CPT-OH & 0.8 & $416,535,-$ & $4.3 \times 10^{5}$ & $0.54(-)$ & $-1.80(-)$ & -5.46 & 2.07 \\
[2]CPT & 54.3 & $446,575,617$ & $3.4 \times 10^{5}$ & $0.32(0.68)$ & $-1.57(-1.86)$ & -5.32 & 1.66 \\
[3]CPT & 34.1 & $432,552,590$ & $4.0 \times 10^{5}$ & $0.45(0.84)$ & $-1.77(-1.98)$ & -5.43 & 1.95 \\
[2]CPTN & - & $442,567,610$ & $2.7 \times 10^{5}$ & $0.34(0.60)$ & $-1.69(-1.92)$ & -5.33 & 1.78 \\
[3]CPTN & - & $430,550,589$ & $4.0 \times 10^{5}$ & $0.44(0.73)$ & $-1.79(-2.04)$ & -5.44 & 2.04 \\
[3]CPTA & - & $428,548,585$ & $6.2 \times 10^{5}$ & $0.49(0.87)$ & $-1.83(-2.10)$ & -5.45 & 2.37 \\
\hline
\end{tabular}

${ }^{a}$ Homodesmotic DFT calculations (B3LYP+D3/def2-TZVP); ${ }^{b}$ Measured in $\mathrm{CH}_{2} \mathrm{Cl}_{2} ;{ }^{c} \mathrm{CH}_{2} \mathrm{Cl}_{2}, \mathrm{TBAPF}_{6}(0.1 \mathrm{M}), 295 \mathrm{~K}, \mathrm{~V}=100 \mathrm{mV} \cdot \mathrm{s}^{-1}$, vs. Fc $/ \mathrm{Fc}$; ${ }^{d} \mathrm{Set} \mathrm{Fc}^{+} / \mathrm{Fc} E_{\mathrm{HOMO}}=-5.1 \mathrm{eV} ;{ }^{e}$ Calculated by the difference of the values of $E^{\text {onset }}{ }_{\text {red1 }}$ and $E^{\text {onset }}{ }_{\text {oxl } 1}$.

of the large amount of ring strain generated and the risk of porphyrin.degradation. ${ }^{10}$ Only when we used the mild reagent $\mathrm{H}_{2} \mathrm{SnCl}_{4}{ }^{11 \mathrm{~d}}$, were we able to isolate compounds [2]CPT and [3]CPT in reasonable three-step yields of $10 \%$ and $6 \%$, respectively. With pure compounds [2]CPT-OH, [2]CPT and [3]CPT in hands, we proceeded to compare key properties by NMR and UV-Vis spectroscopy, cyclic voltammetry and DFT calculations (Table 1). The ${ }^{1} \mathrm{H}$ NMR spectra (Figure 2b) indicate that in contrast to the rectangular precursor (vide supra) the rotation of di-(tert-butyl)phenyl groups is not hindered at room temperature in both [2]CPT and [3]CPT, which is likely a consequence of the strain-induced conical arrangement of these groups. Other notable features in the NMR spectra include significant differences in the chemical shifts of aromatic protons (red in Figure 2b) and two sets of signals for pyrrole protons (" $F$ " and " $E$ "), pointing towards a "ruffle" rather than "saddle" geometry of the porphyrin moieties, which are bent out-ofplane by ca. $35^{\circ}\left(\mathrm{C}_{\text {meso }}-\mathrm{Ni}-\mathrm{C}_{\text {meso }}\right)$.
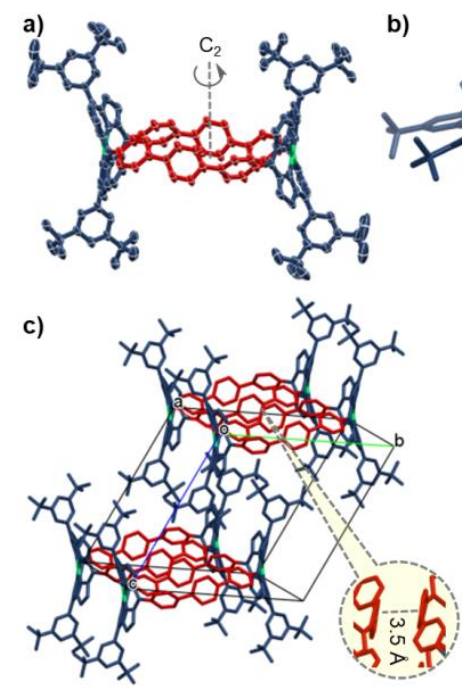

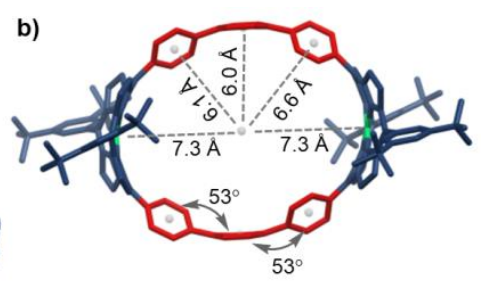

d)

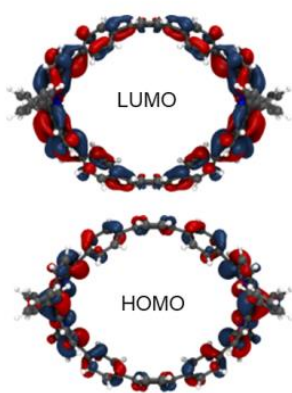

Figure 3. X-ray crystal structure of [2]CPT: (a) ORTEP drawing with $30 \%$ probability. (b) Top view with distances and dihedral angles labeled. (c) Packing in the unit cell. Hydrogen atoms are omitted for clarity. (d) Frontier molecular orbitals of [2]CPT calculated at the B3LYP/def2- TZVP level of theory (isovalue, 0.018).

A solid state structure of [2]CPT could be obtained by synchrotron X-ray diffraction (Figure 3). Single crystals of [2]CPT were prepared by slow evaporation of a solution in $\mathrm{CH}_{3} \mathrm{CN}$ and $\mathrm{CHCl}_{3}$ (1:1). As shown in Figure 3ab, [2]CPT has an oval shape (approximately $C_{2}$ symmetry) with an average diameter of ca. $13.2 \AA$. The dihedral angle between neighboring benzene rings is $53^{\circ}$ and it seems reasonable to assume that the molecule avoids excessive ring strain by placing the two face to face porphyrins out of horizontal line. The packing diagram reveals evidence for intermolecular $\pi-\pi$ interactions between the terphenyl bridges (3.5 ̊, Figure 3c), which leads to "sideway" stacking of the molecules. In the third dimension, this packing leads to uniform pores with "walls" composed nearly exclusively from $\mathrm{sp}^{2}$-hybridized carbon atoms, which could be of interest for future porous energy storage materials. ${ }^{18}$

Optoelectronic Properties. While the unstrained precursor [2]CPT-OH exhibits an absorption spectrum typical for tetraaryl nickel porphyrins, we observed red shifted Soret as well as Q bands and an inversion in the intensity of the $\mathrm{Q}$ bands for the strained macrocycles [3]CPT and [2]CPT. Of note, strain-induced red-shifts are limited to the emission spectra and the ultraviolet part of the spectrum for the related [n]CPPs. ${ }^{\text {a }}$ Compounds [3]CPT and [2]CPT were found to be essentially non-fluorescent, which is typical for $\mathrm{Ni}$ porphyrins however. ${ }^{19}$ Data gathered independently by cyclic voltammetry (Figures S26) and DFT calculations (Figures S46-S48) indicates that the observed bathochromic shifts in the absorption spectrum are to a narrowing of the HOMO/LUMO gap with increasing ring strain. DFT calculations of the frontier molecular orbitals reveal that for both the HOMO and the LUMO the orbital coefficients are delocalized over the entire ring, yet dominant on the porphyrin moieties (Figure 3d). These results suggest that the incorporation of organic semiconductor motifs into nanohoops is a viable strategy to systematically tune the band gaps and absorption maxima. ${ }^{20}$

Fullerene Complexation. We next turned our attention to the inclusion of fullerene guests into the small nanohoop [2]CPT. As shown in Figure 2b, addition of one equivalent $\mathrm{C}_{60}$ led to dramatic changes in all signal sets of the ${ }^{1} \mathrm{H}$ NMR spectrum as well as a splitting of the pyrrole signals. By means of $\mathrm{UV}-\mathrm{V}$ is titrations in toluene (Figure $4 \mathrm{a}$; carried out in triplicate), we were able to determine binding constants of ca. $3 \times 10^{8} \mathrm{M}^{-1}$ for $\mathrm{C}_{60}$ and ca. $2 \times 10^{7} \mathrm{M}^{-1}$ for $\mathrm{C}_{70}$. It is worth noting that the strength of fullerene binding is so high that in the MALDI mass spectrum, where non-covalent interactions are typically broken during ionization, the signal for the radical cation of complex [2]CPT $\supset \mathrm{C}_{60}$ is of the same intensity as that for the parent compound [2]CPT (Figure 4b). MS/MS experiments revealed that the nanohoop carries the positive charge in the radical cations of the complexes [2]CPT $\supset \mathrm{C}_{60 / 70}$ (Figures S51, S52). Collisioninduced dissociation experiments at variable collision energies allowed direct comparison of gas phase relative dissociation energies of fullerene complexes with a monomeric porphyrin (dissociation onset at $\left.\mathrm{E}_{\mathrm{com}}=0.15 \mathrm{eV}\right),[10] \mathrm{CPP}\left(\right.$ onset at $\mathrm{E}_{\mathrm{com}}=0.49$ 
$\mathrm{eV}$ ) and [2]CPT, which in the gas phase binds the larger fullerene $\mathrm{C}_{70}$ slightly more strongly than $\mathrm{C}_{60}$ (onset at $\mathrm{E}_{\mathrm{com}}=0.78$ and $\mathrm{E}_{\mathrm{com}}=0.76 \mathrm{eV}$, respectively).

a)

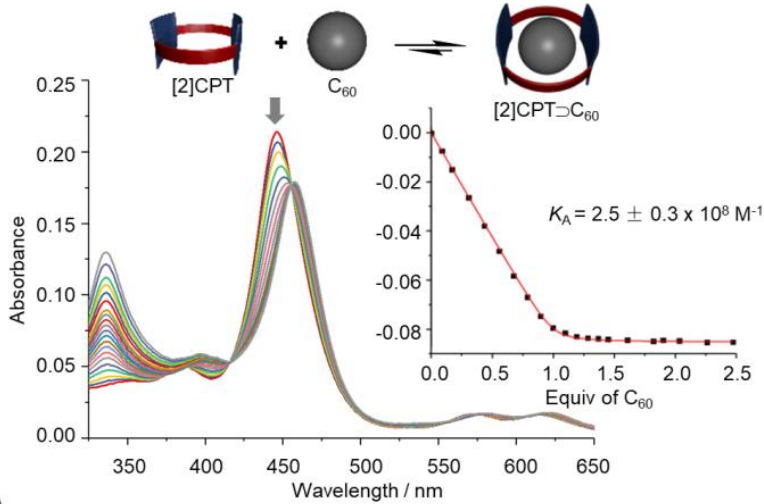

b)
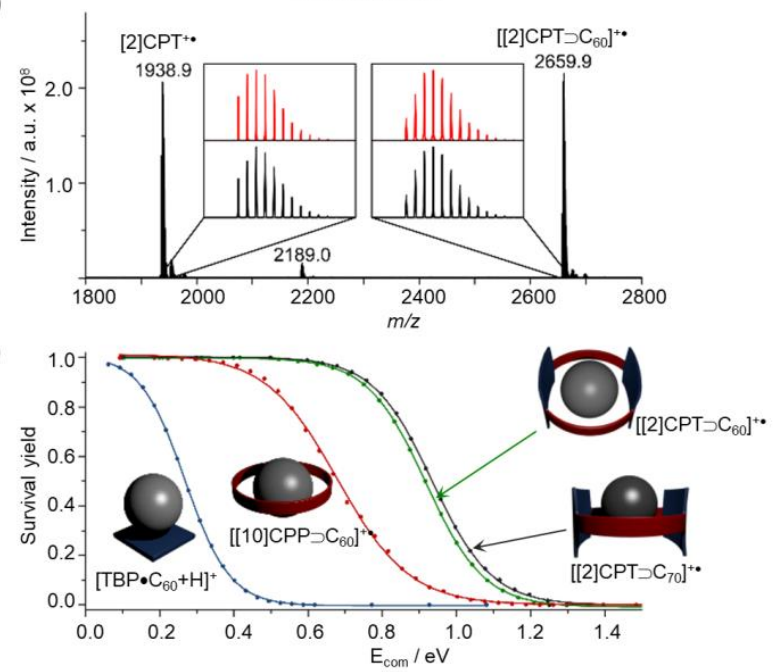

Figure 4. (a) UV-vis titration of [2]CPT with $\mathrm{C}_{60}$ (0-2.5 equiv) in toluene (fit based on 1:1 model). (b) MALDI mass spectrum of [2]CPT $\supset \mathrm{C}_{60}$, (inset shows the experimental and calculated isotopic pattern). (c) Energy-dependent fragmentation experiments for selected fullerene complexes, each fitted with a sigmoidal Boltzmann function (see SI section 8 for details).

Single crystals of the [2]CPT $\supset \mathrm{C}_{60}$ complex were grown by slow diffusion of $\mathrm{CH}_{3} \mathrm{CN}$ into a mixture of $\mathrm{CHCl}_{3}$ and 1,2-dichlorobenzene (1:1). The solid state structure clearly shows that a complex between [2]CPT and $\mathrm{C}_{60}$ with 1:1 stoichiometry is present. As shown in Figure 5a, the encapsulation of $\mathrm{C}_{60}$ is clearly facilitate by convex-concave $\pi$ - $\pi$ interactions (3.4 $\AA \sim 3.7$ $\AA)$ and induces the nanohoop to adopt a more spherical shape. The dihedral angle between neighboring benzene rings decreases to $48^{\circ}$, lending further support to the presence of $\pi-\pi$ interactions between terphenyl bridges and $\mathrm{C}_{60}$. According to the solid state structure, the ${ }^{1} \mathrm{H}$ NMR data and DFT calculations (Figure S40), the diameter of [2]CPT is slightly too small for a "perfect" (symmetric) encapsulation of $\mathrm{C}_{60}$, which results in "off- center" binding with an offset of $1.9 \AA$.

The complex between [2]CPT with $\mathrm{C}_{70}$ was studied using DFT calculations, because high-quality single crystals could not be obtained in this particular case. The calculations once more indicate that the fullerene cannot fully enter into the cavity with an offset distance of $2.7 \AA$, which as expected is larger than the corresponding offset for $\mathrm{C}_{60}$ (Figure $\mathrm{S} 41$ ). This finding provides an evident opportunity to design related fullerene receptors with even higher binding affinities (vide infra). For both the
[2]CPT $\supset \mathrm{C}_{60}$ and [2]CPT $\supset \mathrm{C}_{70}$ complexes, the HOMO orbital coefficients are localized exclusively on porphyrin moieties, while the LUMO orbital coefficients are localized predominately, but not exclusively on the fullerene (Figure 5d, S49). Hence, the DFT calculations suggest that charge transfer plays a role in the non-covalent complexes, which is in agreement with the bathochromic shifts observed during the host-guest titrations (Figure 4a).

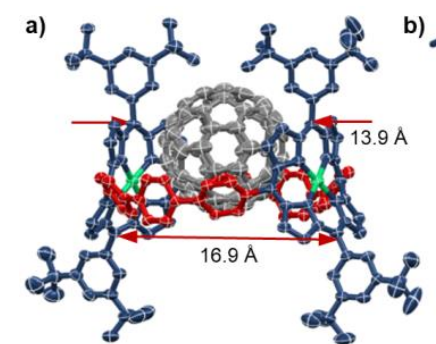

c)

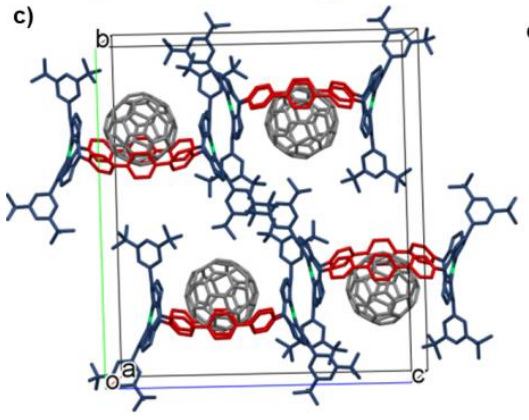

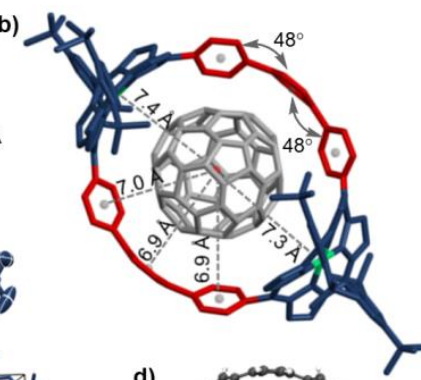

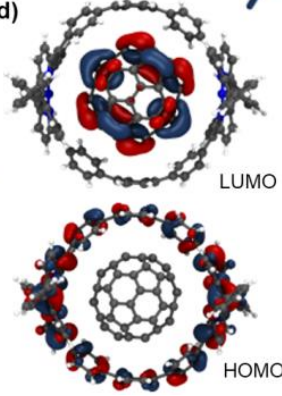

Figure 5. X-ray crystal structure of [2]CPT $\supset \mathrm{C}_{60}$ : (a) ORTEP drawing with $30 \%$ probability. (b) Top view with distances and dihedral angles labeled. (c) Packing in the unit cell. Hydrogen atoms are omitted for clarity. (d) Frontier molecular orbitals of [2]CPT $\supset \mathrm{C}_{60}$ calculated at the B3LYP/ def2- TZVP level of theory (isovalue, 0.018).

$\pi$-Extension of Nanohoops. Several $\pi$-extended CPPs, which can be considered intermediate structures on the way from CPPs to armchair carbon nanotube have been prepared in recent years. ${ }^{21-23} \mathrm{We}$ wondered whether the inclusion of naphthalene or anthracene-moieties would be possible within the [n]CPT architecture. To this end, start our synthesis from commercially available $\alpha$-naphthoquinone and anthraquinone to synthesize the diboronate precursors on a multigram scale. Macrocyclic compounds [n]CPTN-OTES and [n]CPTAOTES $(n=2,3)$ were prepared successfully using the same Suzuki-Miyaura cross-coupling conditions with comparable results to the parent system. The porphyrin macrocycles could also be transformed smoothly into the corresponding alcohols $[\boldsymbol{n}] \mathrm{CPTN}-\mathrm{OH}$ and $[\boldsymbol{n}] \mathrm{CPTA}-\mathrm{OH}$ by treatment with tetrabutylammonium fluoride (TBAF). Strong deviations from the parent system were found in the final step of the synthesis. In case of the naphthyl system, we found that for the small-ring precursor [2]CPTN-OH the final aromatization reaction only proceeded at $70{ }^{\circ} \mathrm{C}$ and gave only $32 \%$ yield of [2]CPTN after 12 hours, whereas the larger [3]CPTN-OH could be easily transformed into [3]CPTN in $82 \%$ yield at room temperature (6 hours). In case of the anthracenyl system, we failed to convert the small-ring precursor [2]CPTA-OH into [2]CPTA (Figure S24) even at elevated temperature, which indicates that the aromatization energy. This interpretation is not only in agreement with Clar's "sectet" theory, ${ }^{24}$ but was corroborated by DFT calculations, which indeed show that there is a difference of about $20 \mathrm{kcal} / \mathrm{mol}$ ( 2 moieties per ring) in the aromatization enthalpy gain between neighbouring compounds in this series (Figure 
6b). Hence, by moving form phenyl (reaction efficient at room temperature) to naphthyl (reaction inefficient at elevated temperature) to anthracenyl (reaction impossible), we seem to have probed the limitations of the aromatization-vs.-strain-generation approach that is so commonly used in this area. ${ }^{25}$ Of note, we can rule out an electronic, and with some confidence also a steric effect, because the larger precursor [3]CPTA-OH could be converted to [3]CPTA in nearly quantitative yield under mild conditions.

The absorption spectrum of the two naphthyl-bridged nanohoops ([2]CPTN, [3]CPTN) are similar to the corresponding [n]CPT nanohoops, but the Soret-band and Q-band absorptions are slightly blue-shifted (Table 1, Figure 6c). The [3]CPTA absorption maximum was further blue-shifted (428 nm, Table 1), but the most striking observation for this compound is the high molar absorption coefficient of the Soret band $\left(\varepsilon=6.2 \times 10^{5} \mathrm{~cm}^{-}\right.$ $\left.{ }^{1} \mathrm{M}^{-1}\right)$, which significantly exceeds those determined for all other nanohoops. Differential-pulse voltammetry and cyclic voltammetry experiments of [n]CPTN and [3]CPTA (Figure S26) revealed that these nanohoops exhibit a slightly increased HOMO/LUMO gap when compared to their CPT analogues. ${ }^{23 a}$

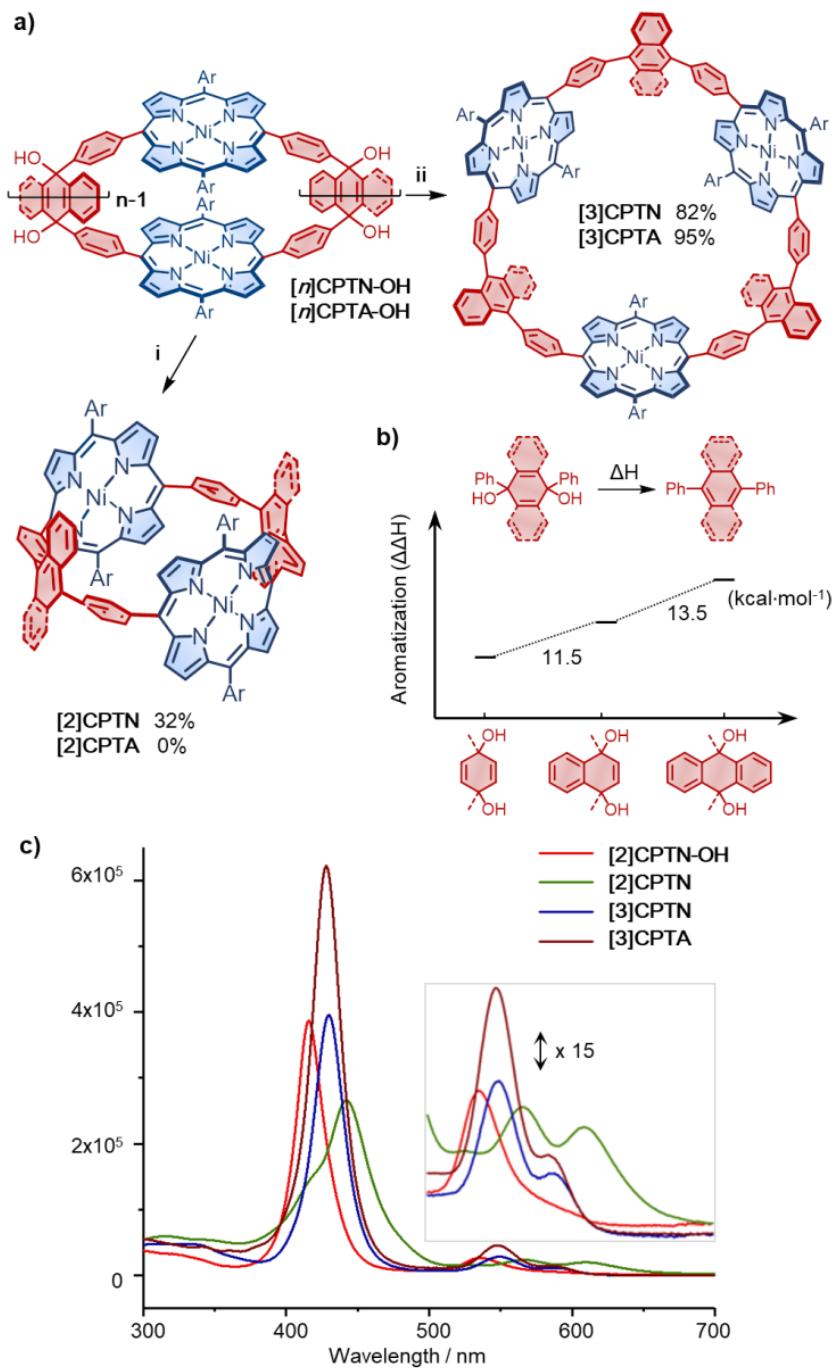

Figure 6. (a) Synthesis of the $[\boldsymbol{n}] \mathrm{CPTN}$ and $[\boldsymbol{n}]$ CPTA: (i) $\mathrm{H}_{2} \mathrm{SnCl}_{4}$, $\mathrm{RT} \rightarrow 70{ }^{\circ} \mathrm{C}$, THF, 12 h. (ii) $\mathrm{H}_{2} \mathrm{SnCl}_{4}, \mathrm{RT}, 12 \mathrm{~h}$ ([3]CPTN). NaI, $\mathrm{NaH}_{2} \mathrm{PO}_{2}, \mathrm{AcOH}, 100{ }^{\circ} \mathrm{C}, 6 \mathrm{~h}$ ([3]CPTA). (b) Relative differences in the aromatization enthalpies as calculated at the B3LYP+D3/def2TZVPP level of theory. (c) UV-vis absorption spectra of [2]CPTN-OH

(light red) [2]CPTN (light green) [3]CPTN (blue) and [3]CPTA (dark red).

Depending on the rotation rate of the phenyl-naphthyl C-C bonds, the $\pi$-extended nanohoops of type [n]CPTN can in principle exist as two different stereoisomers, which is why we conducted an NMR study to shed light on this issue. The ${ }^{1} \mathrm{H}$ NMR spectra of [2]CPTN and [3]CPTN showed only one set of signals at room temperature, indicating either fast rotation of the $\mathrm{C}-\mathrm{C}$ bonds or the presence of only one stereoisomer. Conclusive evidence to this end was obtained by variable temperature NMR (VT-NMR). The $t$-Bu group signal of [2]CPT, [2]CPTN and [3]CPTN splits into two peaks at low temperature (ca. 240 $\mathrm{K}, 230 \mathrm{~K}$ and $250 \mathrm{~K}$, respectively), which we attribute to the slow rotation of the porphyrin- $(t \mathrm{Bu})_{2}$-phenyl $\mathrm{C}-\mathrm{C}$ bond (see Figures S9, S16, S20, S21 for VT-NMR spectra and Eyring analyses). Evidence for a restricted rotation of the naphthalene units within the nanohoops was not observed over the investigated temperature range (minimum temperature: $250 \mathrm{~K}$ ).

To test the limits of fullerene affinity in these new nanohoop architectures, we studied the thermodynamics of [2]CPTN $\supset$ fullerene complexes. UV-Vis titrations revealed an association constant of $3.0 \times 10^{8} \mathrm{M}^{-1}$ (toluene) for [2] CPTN $\supset \mathrm{C}_{60}$ (Figure S32), which is identical within error with the [2]CPT $\supset \mathrm{C}_{60}$ complex and indicates that the $\pi$-extension of the nanohoop seemingly does not improve the "contact area" between $\mathrm{C}_{60}$ and the nanohoop. In contrast, when the [2]CPTN $\supset \mathrm{C}_{70}$ complex was studied in the same way, an increase of the binding constant $\left(1.0 \times 10^{8} \mathrm{M}^{-1}\right.$, toluene $)$ by a factor of five was observed in comparison to the parent system (Figure $7 \mathrm{c})$. This finding can be rationalized by the larger VdW surface of $\mathrm{C}_{70}$, and indeed this hypothesis was supported by DFT calculations (Figure 7b).

a)

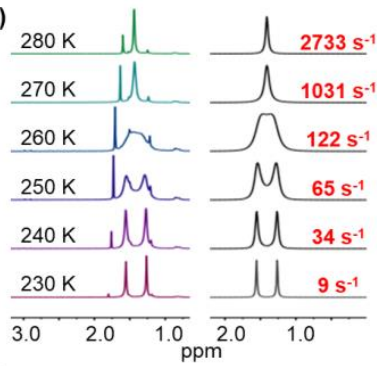

c)

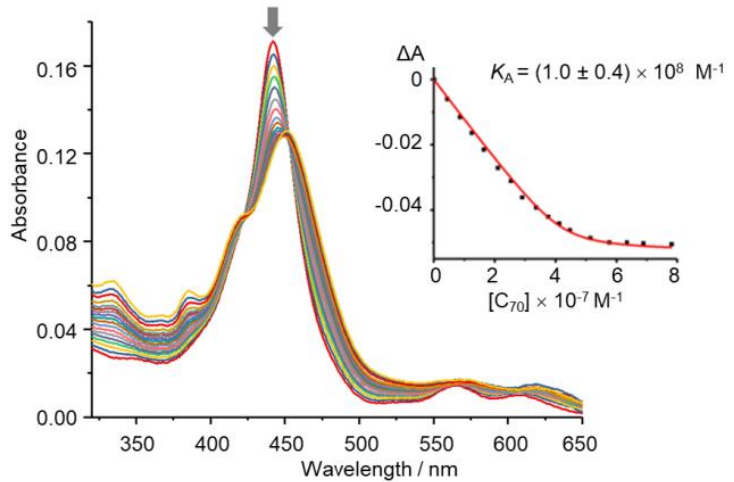

Figure 7. (a) Experimental (left) and simulated (right) ${ }^{1} \mathrm{H}$ NMR spectra of [3]CPTN at various temperatures. (b) Optimized geometries of [2]CPTN $\supset \mathrm{C}_{70}$ obtained by DFT calculations at the PBE+D3 level of theory, side chains of [2]CPTN omitted for clarity. (c) UV-vis titration of [2]CPTN with $\mathrm{C}_{70}$ (0-1.9 equiv) in toluene (fit based on 1:1 model). 


\section{CONCLUSIONS}

In conclusion, we developed a concise synthesis of a series of strained porphyrin macrocycles, which due to their unique molecular design offer opportunities for uses in bimetallic catalysis and crystal engineering. The two nanohoops [2]CPT and [2]CPTN can be considered porphyrinogenic equivalents to [10]CPP, albeit with ca. 100-fold increased affinity for fullerenes, which may prove useful for the regioselective synthesis or separation of fullerene bisadducts ${ }^{14,26}$ and in photoelectroactive devices $^{27}$. We also observed unusual optoelectronic properties, most importantly, a strain-induced red-shift of absorption in the visible range of the spectrum, which may inspire further studies on the bending of organic semiconductors ${ }^{28}$ or molecular switches. $^{29}$

\section{ASSOCIATED CONTENT}

Supporting Information. Synthesis and characterization data. Details on mass spectrometric, variable-temperature NMR, UV-Vis titrations and theoretical calculations. This material is available free of charge via the Internet at http://pubs.acs.org.

Crystallographic data for [2]CPT-OH (CIF)

Crystallographic data for [2]CPT (CIF)

Crystallographic data for [2]CPT $\supset \mathrm{C}_{60}(\mathrm{CIF})$

\section{AUTHOR INFORMATION}

\author{
Corresponding Author \\ *max.vondelius@uni-ulm.de \\ *bernd.meyer@fau.de,
}

\section{Notes}

The authors declare no competing financial interest

\section{ACKNOWLEDGMENT}

We are grateful for financial support from the Deutsche Forschungsgemeinschaft (DFG, project number 182849149-SFB953 "Synthetic Carbon Allotropes"), the University of Ulm, and FAU Erlangen-Nürnberg. I.I. thanks the Severo Ochoa Center of Excellence Program (ICN2, Grant SEV-2017-0706) and X.R. thank ICREA-Acadèmia award.

\section{REFERENCES}

(1) (a) Darzi, E. R.; Jasti, R. The Dynamic, Size-Dependent Properties of [5]-[12]Cycloparaphenylenes. Chem. Soc. Rev. 2015, 44, 64016410. (b) Bols, P. S.; Anderson, H. L. Template-directed Synthesis of Molecular Nanorings and Cages. Acc. Chem. Res. 2018, 51, 20832092. (c) Xu, Y.; von Delius, M. The Supramolecular Chemistry of Strained Carbon Nanohoops. Angew. Chem., Int. Ed. 2019, 58, doi: 10.1002/anie.201906069.

(2) (a) Aratani, N.; Kim, D.; Osuka, A. Discrete Cyclic Porphyrin Arrays as Artificial Light-Harvesting Antenna. Acc. Chem. Res. 2009, 42, 1922-1934. (b) Anderson, S.; Anderson, H. L.; Sanders, J. K. M. Expanding Roles for Templates in Synthesis. Acc. Chem. Res. 1993, 11, 469-475. (c) Jiang, H.; Tanaka, T.; Mori, H.; Park, K. H.; Kim, D.; Osuka, A. Cyclic 2,12-Porphyrinylene Nanorings as a Porphyrin Analogue of Cycloparaphenylenes. J. Am. Chem. Soc. 2015, 137, 2219-2222.

(3) (a) Tashiro, K.; Aida, T. Metalloporphyrin Hosts for Supramolecular Chemistry of Fullerenes. Chem. Soc. Rev. 2007, 189-197. (b) Yanagisawa, M.; Tashiro, K.; Yamasaki, M.; Aida, T. Hosting Fullerenes by Dynamic Bond Formation with an Iridium Porphyrin Cyclic Dimer: A "Chemical Friction" for Rotary Guest Motions. J. Am. Chem. Soc. 2007, 129, 11912-11913. (c) Song, J.; Aratani, N.; Shinokubo, H.; Osuka, A. A Porphyrin Nanobarrel That Encapsulates $\mathrm{C}_{60} . J . A m$. Chem. Soc. 2010, 132, 16356-16357. (d) Kieran, A. L.; Pascu, S. I.; Jarrosson, T.; Sanders, J. K. M. Inclusion of $\mathrm{C}_{60}$ into an Adjustable Porphyrin Dimer Generated by Dynamic Disulfide Chemistry. Chem. Commun. 2005, 1276-1278. (e) Tashiro, K.; Hirabayashi, Y.; Aida, T.; Saigo, K.; Fujiwara, K.; Komatsu, K.; Sakamoto, S.; Yamaguchi, K. A Supramolecular Oscillator Composed of Carbon Nanocluster $\mathrm{C}_{120}$ and a Rhodium(III) Porphyrin Cyclic Dimer. J. Am. Chem. Soc. 2002, 124, 12086-12087. (f) Nobukuni, H.; Shimazaki, Y.; Tani, F.; Naruta, Y. A Nanotube of Cyclic Porphyrin Dimers Connected by Nonclassical Hydrogen Bonds and Its Inclusion of $\mathrm{C}_{60}$ in a Linear Arrangement. Angew. Chem., Int. Ed. 2007, 46, 8975-8978. (g) Xue, S.; Kuzuhara, D.; Aratani, N.; Yamada, H. Synthesis of a Porphyrin(2.1.2.1) Nanobelt and Its Ability to Bind Fullerene. Org. Lett. 2019, 21, 2069-2072. (h) Gil-Ramírez, G.; Karlen, S. D.; Shundo, A.; Porfyrakis, K.; Ito, Y.; Briggs, G. A. D.; Morton, J. J. L.; Anderson, H. L. A Cyclic Porphyrin Trimer as a Receptor for Fullerenes. Org. Lett. 2010, 12, 3544-3547.

(4) Walter, C. J.; Anderson, H. L.; Sanders, J. K. M. Q. exo-Selective Acceleration of an Intermolecular Diels-Alder Reaction by a Trimeric Porphyrin Host. J. Chem. Soc. Chem. Commun. 1993, 458, 458-460.

(5) (a) Hoffmann, M.; Wilson, C. J.; Odell, B.; Anderson, H. L. Template - Directed Synthesis of a $\pi$-Conjugated Porphyrin Nanoring. Angew. Chem., Int. Ed. 2007, 46, 3122-3125. (b) Rickhaus, M.; Vargas Jentzsch, A.; Tejerina, L.; Grübner, I.; Jirasek, M.; Claridge, T. D. W.; Anderson, H. L. Single-Acetylene Linked Porphyrin Nanorings. J. Am. Chem. Soc. 2017, 139, 16502-16505.

(6) Anderson, H. L.; Sanders, J. K. M. Amine-Template-Directed Synthesis of Cyclic Porphyrin Oligomers. Angew. Chem., Int. Ed. 1990, 29, 1400-1403.

(7) Peeks, M. D.; Claridge, T. D. W.; Anderson, H. L. Aromatic and Aantiaromatic Ring Currents in a Molecular Nanoring. Nature 2017, 541, 200-203.

(8) Peeks, M. D.; Tait, C. E.; Neuhaus, P.; Fischer, G. M.; Hoffmann, M.; Haver, R.; Cnossen, A.; Harmer, J. R.; Timmel, C. R.; Anderson, H. L. Electronic Delocalization in the Radical Cations of Porphyrin Oligomer Molecular Wires. J. Am. Chem. Soc. 2017, 139, 1046110471.

(9) Liu, P.; Hisamune, Y.; Peeks, M. D.; Odell, B.; Gong, J. Q.; Herz, L. M.; Anderson, H. L. Synthesis of Five-Porphyrin Nanorings by Using Ferrocene and Corannulene Templates. Angew. Chem., Int. Ed. 2016, 55, 8358-8362.

(10) Jiang, H; Tanaka, T.; Kim, T.; Sung, Y. M.; Mori, H.; Kim, D.; Osuka, A. Synthesis of $[n]$ Cyclo-5,15-porphyrinylene-4,4'biphenylenes Displaying Size-Dependent Excitation-Energy Hopping Angew. Chem., Int. Ed. 2015, 54, 15197-15201.

(11) (a) Jasti, R.; Bhattacharjee, J.; Neaton, J. B.; Bertozzi, C. R. Synthesis, Characterization, and Theory of [9]-, [12]-, and [18]Cycloparaphenylene: Carbon Nanohoop Structures. J. Am. Chem. Soc. 2008, 130, 17646-17647. (b) Golder, M. R.; Jasti, R. Syntheses of the Smallest Carbon Nanohoops and the Emergence of Unique Physical Phenomena. Acc. Chem. Res. 2015, 48, 557-566. (c) Takaba, H.; Omachi, H.; Yamamoto, Y.; Bouffard, J.; Itami, K. Selective Synthesis of [12]Cycloparaphenylene. Angew. Chem., Int. Ed. 2009, 48, 61126116. (d) Patel, V. K.; Kayahara, E.; Yamago, S. Practical Synthesis of $[n]$ Cycloparaphenylenes $(\mathrm{n}=5,7-12)$ by $\mathrm{H}_{2} \mathrm{SnCl}_{4}$-Mediated Aromatization of 1,4-Dihydroxycyclo-2,5-diene Precursors. Chem. - Eur. J. 2015, 21, 5742-5749. (e) Iwamoto, T.; Watanabe, Y.; Sakamoto, Y.; Suzuki, T.; Yamago, S. Selective and Random Syntheses of $[n]$ Cycloparaphenylenes $(\mathrm{n}=8-13)$ and Size Dependence of Their Electronic Properties. J. Am. Chem. Soc. 2011, 133, 8354-8361. (f) Lu, D.; Zhuang, G.; Wu, H.; Wang, S.; Yang, S.; Du, P. A Large $\pi$-Extended Carbon Nanoring Based on Nanographene Units: Bottom-Up Synthesis, Photophysical Properties, and Selective Complexation with Fullerene C70. Angew. Chem., Int. Ed. 2017, 56, 158-162. (g) Lu, D.; Cui, S.; Du, $\mathrm{P}$. Large $\pi$-Extension of Carbon Nanorings by Incorporating Hexa-peri- 
hexabenzocoronenes. Synlett, 2017, 28, 1671-1677. (h) Hitosugi, S.; Nakanishi, W.; Yamasaki, T.; Isobe, H. Bottom-up Synthesis of Finite Models of Helical (n,m)-Single-wall Carbon Nanotubes. Nat. Commun. 2011, 2, 492. (i) Kawase, T. Darabi, H. R.; Oda, M. Cyclic [6]- and [8]Paraphenylacetylenes. Angew. Chem., Int. Ed. Engl. 1996, 35, 2664-2666. (j) Lee, S.; Chenard, E.; Gray, D. L. Moore, J. S. Synthesis of Cycloparaphenyleneacetylene via Alkyne Metathesis: $\mathrm{C}_{70}$ Complexation and Copper-Free Triple Click Reaction. J. Am. Chem. Soc. 2016, 138, 13814-13817. (k) Povie, G.; Segawa, Y.; Nishihara, T.; Miyauchi, Y.; Itami, K. Synthesis of a Carbon Nanobelt. Science 2017, 356, 172-175. (1) Cheung, K. Y.; Gui, S.; Deng, C.; Liang, H.; Xia, Z.; Liu, Z.; Chi, L.; Miao, Q. Synthesis of Armchair and Chiral Carbon Nanobelts. Chem 2019, 5, 838-847. (m) Senthilkumar, K.; Kondratowicz, M.; Lis, T.; Chmielewski, P. J.; Cybińska, J.; Zafra, J. L.; Casado, J.; Vives, T.; Crassous, J.; Favereau, L.; Stępień, M. Lemniscular [16]Cycloparaphenylene: A Radially Conjugated FigureEight Aromatic Molecule. J. Am. Chem. Soc. 2019, 141, 7421-7427. (n) Segawa, Y.; Kuwayama, M.; Hijikata, Y.; Fushimi, M.; Nishihara, T.; Pirillo, J.; Shirasaki, J.; Kubota, N.; Itami, K. Topological Molecular Nanocarbons: All-benzene Catenane and Trefoil Knot. Science 2019, 276, 272-276.

(12) (a) Iwamoto, T.; Watanabe, Y.; Sadahiro, T.; Haino, T.; Yamago, S. Size-Selective Encapsulation of $\mathrm{C}_{60}$ by [10]Cycloparaphenylene: Formation of the Shortest Fullerene-Peapod. Angew. Chem., Int. Ed. 2011, 50, 8342-8344. (b) Xia, J.; Bacon, J. W.; Jasti, R. Gram-Scale Synthesis and Crystal Structures of [8]- and [10]CPP, and the SolidState Structure of $\mathrm{C}_{60} @$ [10]CPP. Chem. Sci. 2012, 3, 3018-3021.

(13) Xu, Y.; Wang, B.; Kaur, R.; Minameyer, M.; Bothe, M.; Drewello, T.; Guldi, D.; von Delius, M. A Supramolecular [10]CPP Junction Enables Efficient Electron Transfer in Modular Porphyrin[10]CPP $\supset$ Fullerene Complexes. Angew. Chem., Int. Ed. 2018, 57, $11549-11553$.

(14) Xu, Y.; Kaur, R.; Wang, B.; Minameyer, M.; Gsänger, S.; Meyer, B.; Drewello, T.; D. Guldi, M. von Delius, M. Concave-Convex $\pi-\pi$ Template Approach Enables the Synthesis of [10]Cycloparaphenylene-Fullerene [2]Rotaxanes. J. Am. Chem. Soc. 2018, 140, 13413 13420.

(15) To allow adequate comparisons with literature values, we provide calculated strain energies based on the B3LYP functional and a homodesmotic reaction model in this article. More comprehensive data on ring strain is provided in the SI, section 7.

(16) (a) Evans, P. J.; Darzi, E. R.; Jasti, R. Efficient Room-Temperature Synthesis of a Highly Strained Carbon Nanohoop Fragment of Buckminsterfullerene. Nat. Chem. 2014, 6, 404-408. (b) Kayahara, E.; Patel, V. K.; Yamago, S. Synthesis and Characterization of [5]Cycloparaphenylene. J. Am. Chem. Soc. 2014, 136, 2284-2287.

(17) Oldacre, A. N.; Crawley, M. R.; Friedman, A. E.; Cook, T. R. Tuning the Activity of Heterogeneous Cofacial Cobalt Porphyrins for Oxygen Reduction Electrocatalysis through Self-Assembly. Chem. Eur. J. 2018, 24, 10984-10987.

(18) Sakamoto, H.; Fujimori, T.; Li, X.; Kaneko, K.; Kan, K.; Ozaki, N.; Hijikata, Y.; Irle, S.; Itami, K. Cycloparaphenylene as a Molecular Porous Carbon Solid with Uniform Pores Exhibiting Adsorption-Induced Softness. Chem. Sci. 2016, 7, 4204-4210.

(19) McCarthy, J. R.; Weissleder, R. Model Systems for Fluorescence and Singlet Oxygen Quenching by Metalloporphyrins. ChemMedChem 2007, 2, 360-365.

(20) (a) Zhylitskaya, H.; Cybińska, J.; Chmielewski, P.; Lis,T.; Stępień, M. Bandgap Engineering in $\pi$-Extended Pyrroles. A Modular Approach to Electron-Deficient Chromophores with Multi-Redox Activity. $J$. Am. Chem. Soc. 2016, 138, 11390-11398. (b) Haddad, R. E.; Gazeau, S.; Pécaut, J.; Marchon, J. C.; Medforth, C. J.; Shelnutt, J. A. Origin of the Red Shifts in the Optical Absorption Bands of Nonplanar Tetraalkylporphyrins. J. Am. Chem. Soc. 2003, 125, 1253-1268. (c) Würthner, F.; Saha-Möller, C. R.; Fimmel, B.; Ogi, S.; Leowanawat, P.; Schmidt, D. Perylene Bisimide Dye Assemblies as Archetype Functional Supramolecular Materials. Chem. Rev. 2016, 116, 962-1052.

(21) (a) Jia, H.; Gao, Y.; Huang, Q.; Cui, S.; Du, P. Facile Three-Step Synthesis and Photophysical Properties of [8]-, [9]-, and [12]Cyclo1,4-naphthalene Nanorings via Platinum-Mediated Reductive Elimination. Chem. Commun. 2018, 54, 988-991. (b) Yagi, A.; Segawa, Y.; Itami, K. J. Am. Chem. Soc. 2012, 134, 2962-2965.

(22) (a) Huang, Z.; Chen, C.; Yang, X.; Fan, X.; Zhou, W.; Tung, C.; $\mathrm{Wu}$, L.; Cong, H. Synthesis of Oligoparaphenylene-Derived Nanohoops Employing an Anthracene Photodimerization-Cycloreversion Strategy. J. Am. Chem. Soc. 2016, 138, 11144-11147. (b) Xu, W.; Yang, X.; Fan, X.; W, X.; Tung, C. Wu, Li., Cong, H. Synthesis and Characterization of a Pentiptycene-Derived Dual Oligoparaphenylene Nanohoop. Angew. Chem. 2019, 131, 3983-3987. (c) Della Sala, P.; Capobianco, A.; Caruso, T.; Talotta, C.; De Rosa, M.; Neri, P.; Peluso, A.; Gaeta, C. An Anthracene-Incorporated [8]Cycloparaphenylene Derivative as an Emitter in Photon Upconversion. J. Org. Chem. 2018, 83, 220-227.

(23) (a) Iwamoto, T.; Kayahara, E.; Yasuda, N.; Suzuki, T.; Yamago, S. Synthesis, Characterization, and Properties of [4]Cyclo-2,7pyrenylene: Effects of Cyclic Structure on the Electronic Properties of Pyrene Oligomers. Angew. Chem., Int. Ed. 2014, 53, 6430-6434. (b) Yagi, A.; Venkataramana, G.; Segawa, Y.; Itami, K. Synthesis and Properties of Cycloparaphenylene-2,7-pyrenylene: a Pyrene-Containing Carbon Nanoring. Chem. Commun. 2014, 50, 957-959.

(24) Clar, E. The aromatic sextet; John Wiley \& Sons LTD, London, 1972.

(25) Lewis, S. E. Cycloparaphenylenes and Related Nanohoops. Chem. Soc. Rev. 2015, 44, 2221-2304.

(26) (a) Brenner, W.; Ronson, T. K.; Nitschke, J. R. Separation and Selective Formation of Fullerene Adducts within an $\mathrm{M}^{\mathrm{II}}{ }_{8} \mathrm{~L}_{6}$ Cage. $J$. Am. Chem. Soc. 2017, 139, 75-78. (b) Wood, C. S.; Browne, C.; Wood, D. M.; Nitschke, J. R. Fuel-Controlled Reassembly of Metal-Organic Architectures. ACS Cent. Sci. 2015, 1, 504-509. (c) Fuertes-Espinosa, C.; Gómez-Torres, A.; Morales-Martínez, R.; Rodríguez-Fortea, A.; Echegoyen, L.; et al. Purification of Uranium-based Endohedral Metallofullerenes (EMFs) by Selective Supramolecular Encapsulation and Release. Angew. Chem., Ed. 2018, 57, 11294-11299.

(27) Huang, Q.; Zhuang, G.; Jia, H.; Qian, M.; Cui, S.; Yang, S.; Du, P. Photoconductive Curved-Nanographene/Fullerene Supramolecular Heterojunctions. Angew. Chem., Int. Ed. 2019, 58, 6244-6249.

(28) (a) Zhang, B.; Trinh, M. T.; Fowler, B.; Ball, M.; Xu, Q. Ng, F.; Steigerwald, L. M.; Zhu, X.; Nuckolls, C.; Zhong, Y. Rigid, Conjugated Macrocycles for High Performance Organic Photodetectors. $J$. Am. Chem. Soc. 2016, 138, 16426-16431. (b) Ball, M.; Zhang, B.; Zhong, Y.; Fowler, B.; Xiao, S.; Ng, F.; Steigerwald, M.; Nuckolls, C. Conjugated Macrocycles in Organic Electronics. Acc. Chem. Res. 2019, 52, 1068-1078.

(29) Bléger, D.; Hecht, S. Visible-Ligh-Activated Molecular Switches. Angew. Chem., Int. Ed. 2015, 54, 11338-11349. 


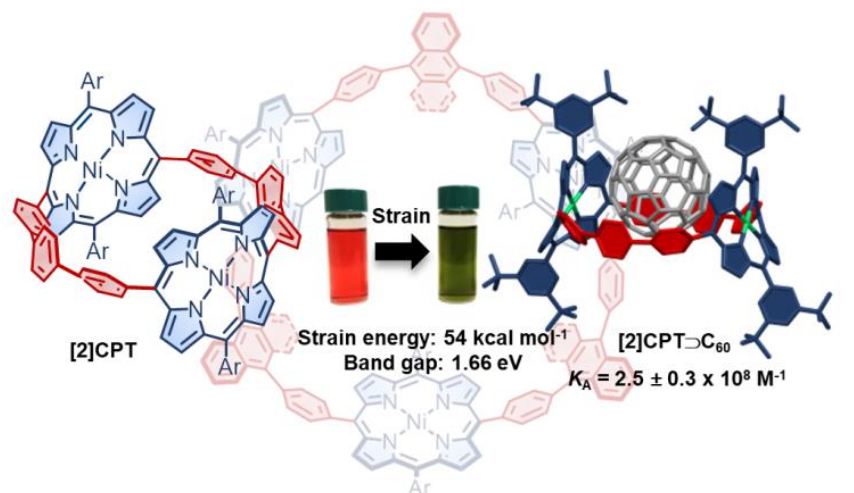

